Revista Brasil. Bot., V.32, n.3, p.571-585, jul.-set. 2009

\title{
Efeito de diferentes níveis de enriquecimento por fósforo sobre a estrutura da comunidade perifítica em represa oligotrófica tropical (São Paulo, Brasil)
}

\author{
CARLA FERRAGUT ${ }^{1,2}$ e DENISE DE CAMPOS BICUDO ${ }^{1}$
}

(recebido: 17 de abril de 2008; aceito: 24 de junho de 2009)

\begin{abstract}
Effect of different levels of phosphorus enrichment on periphyton community structure in a tropical oligotrophic reservoir (São Paulo, Brazil)). Nutrient diffusing substrata (NDS) were used to determine the effect of added phosphorus on the periphyton development in a shallow reservoir (Lago do IAG, PEFI, São Paulo). Three treatments $(n=2)$ were designed: control (without phosphorous addition) and two levels of phosphorus addition $\left(\mathrm{P}_{1}=0.1 \mathrm{M}\right.$ and $\left.\mathrm{P}_{2}=0.5 \mathrm{M} \mathrm{KH}_{2} \mathrm{PO}_{4}\right)$. NDS surface was covered with a $20 \mu \mathrm{m}$ mesh cloth for periphyton growth. Samplings were carried at 15, 20, 25 and 30 days of colonization. Biomass accumulation (organic matter, chlorophyll-a, total algal biovolume) and total algal density did not show significant response to nutrient addition. Seven species of chlorophytes and one of diatoms were closely associated to P availability. Periphyton nutrient status $(\mathrm{P} \%, \mathrm{~N} \%, \mathrm{~N}: \mathrm{P})$ demonstrated $\mathrm{P}$-limitation as well as reinforced periphyton $\mathrm{P}$ retention capacity. Periphyton attributes were more sensible to $\mathrm{P}$ enrichment than to the different addition levels, indicating further N-limitation. Comparison with previous data indicated temporal (1996-2002) increase in the reservoir phosphorus availability, although P-limitation is still prevalent. Periphyton, on the basis of its nutrient status and species structure, was sensible to temporal shift on phosphorus availability and P-addition, reinforcing its potential as an evaluating tool for early signs of eutrophication.
\end{abstract}

Key words - algae, environmental descriptors, periphyton, phosphorus, reservoir

RESUMO - (Efeito de diferentes níveis de enriquecimento por fósforo sobre a estrutura da comunidade perifítica em represa oligotrófica tropical (São Paulo, Brasil)). Substrato difusor de nutrientes (SDN) foi utilizado para determinar o efeito da adição de fósforo sobre o desenvolvimento do perifíton em uma represa rasa (Lago do IAG, PEFI, São Paulo). Três tratamentos $(n=2)$ foram delineados: controle (sem adição de fósforo) e dois com adição de fósforo $\left(\mathrm{P}_{1}=0,1 \mathrm{M} \mathrm{e} \mathrm{P}_{2}=0,5 \mathrm{M} \mathrm{KH}_{2} \mathrm{PO}_{4}\right)$. A superfície dos SDN foi revestida com malha de $20 \mu \mathrm{m}$ para crescimento do perifíton. Coletas foram realizadas nos $15^{\circ}$, 20, $25^{\circ}$ e $30^{\circ}$ dias de colonização. A acumulação de biomassa (massa orgânica, clorofila-a, biovolume total de algas) e de densidade total de algas não forneceu resposta significativa ao enriquecimento. Seis espécies de clorofíceas e uma de diatomáceas associaram-se à disponibilidade de fósforo. $\mathrm{O}$ estado nutricional do perifíton $(\% \mathrm{P}, \% \mathrm{~N}, \mathrm{~N}: \mathrm{P})$ demonstrou a limitação pelo fósforo, bem como reforçou a capacidade da comunidade na retenção do fósforo. Os atributos do perifíton foram mais sensíveis ao enriquecimento pelo fósforo, do que aos níveis de adição, indicando que a comunidade passou a ser limitada pelo nitrogênio. A comparação com dados anteriores indicou aumento temporal (1996-2002) da disponibilidade de fósforo na represa, embora ainda prevalecendo condição P-limitante. O perifíton, por meio de seu estado nutricional e estrutura de espécies, foi sensível às alterações temporais de disponibilidade de fósforo e ao enriquecimento experimental, reforçando seu potencial como ferramenta avaliadora de sinais precoces de eutrofização.

Palavras-chave - algas, descritores ambientais, fósforo, perifíton, reservatório

\section{Introdução}

O fósforo é tido como elemento-chave na regulação da produtividade dos ecossistemas e, talvez, seja o nutriente mais importante na maioria dos ecossistemas dulciaquícolas (Brezonik \& Pollman 1999). É frequentemente reportado como nutriente limitante do crescimento algal em diferentes regiões climáticas do globo (Hecky \& Kilham 1988, Reynolds \& Davies 2001), podendo atuar de forma indireta sobre vários

1. Instituto de Botânica, Seção de Ecologia, 04301-012 São Paulo, SP, Brasil.

2._Autor para correspondência: carlaferragut@yahoo.com.br processos, como sobre o fluxo e dinâmica do nitrogênio em ecossistemas oligotróficos (Dodds \& Priscu 1990) e até mesmo levando à limitação por outros nutrientes, como a sílica (Schelske \& Stoermer 1971).

Estudos sobre fontes e biodisponibilidade de fósforo na água doce reportam esse elemento como agente primário do processo de eutrofização, pois o aumento adicional da biomassa de produtores primários está diretamente ligado à aceleração antropogênica do aporte das frações de fósforo biologicamente disponíveis (Reynolds \& Davies 2001). Como o enriquecimento por fósforo é frequentemente documentado como o fator que, usualmente, mais afeta a integridade dos ecossistemas de águas doces, indicadores biológicos rápidos vêm sendo 
propostos a fim de detectar impactos relacionados ao aporte desse nutriente (Newman et al. 2003).

O perifíton tem sido sugerido como um importante indicador precoce do processo da eutrofização (McCormick \& O’Dell 1996, McCormick \& Stevenson 1998, Dodds 2003). Possui atributos importantes para bioindicação, tais como: ampla distribuição nos ecossistemas aquáticos; modo de vida séssil, ou seja, não migra em condições adversas; é geralmente rico em espécies, sendo um sistema rico de informações ecológicas; as espécies apresentam ciclos-de-vida curtos, de forma a responderem mais rapidamente às alterações ambientais quando comparadas a outros organismos, tais como invertebrados bentônicos ou macroalgas (Lowe \& Pan 1996, McCormick \& Stevenson 1998, Newman et al. 2003). Mais recentemente, índices perifíticos multimétricos de integridade biótica que foram propostos para os Everglades, na Flórida (McCormick et al. 2001), bem como para sistemas lóticos da região dos Apalaches (Hill et al. 2000) vêm sendo utilizados para o diagnóstico de impacto ambiental e para estabelecer metas de recuperação dos ecossistemas.

As características do perifíton acima mencionadas impulsionaram os trabalhos experimentais sobre o entendimento das alterações da estrutura do perifíton em condições de enriquecimento artificial isolado e/ou combinado de nitrogênio e fósforo. Entretanto, os estudos estão ainda concentrados em região de clima temperado (DeNicola et al. 2006) e subtropical (Pan et al. 2000), sendo bem mais restritos em regiões tropicais do globo. Em especial para o Brasil, exceto aos trabalhos de Engle \& Melack (1993) e Mendes \& Barbosa (2002), respectivamente realizados em lagoa marginal da Amazônia e em riacho de Minas Gerais, os demais estudos foram desenvolvidos em represas do Estado de São Paulo (Cerrao et al. 1991, Ferragut 1999, Fermino 2006, Vercellino 2007). Uma síntese preliminar sobre a avaliação da limitação de nutrientes ao crescimento do fitoplâncton e perifíton no Brasil e, especificamente para a área de estudo (PEFI - Parque Estadual das Fontes do Ipiranga), apontou o fósforo como o elemento mais comumente limitante (Huszar et al. 2005).

Particularmente as modificações da comunidade perifítica frente aos níveis crescentes de fósforo e em condições controladas são bem menos compreendidas tanto em ecossistema lótico (Bothwell 1988, Horner et al. 1990) quanto lêntico (Pan et al. 2000), inexistindo esta abordagem no Brasil.

O presente estudo tem os seguintes objetivos: (a) investigar a influência de diferentes níveis de enriquecimento por fósforo sobre a estrutura em nível de espécies de algas, biomassa e estado nutricional da comunidade perifítica; (b) identificar os principais atributos indicadores da disponibilidade de fósforo e (c) avaliar guildas de algas perifíticas indicadoras da disponibilidade de fósforo em represa oligotrófica tropical. Pretende, assim, contribuir para estudos de qualidade ecológica, particularmente, voltados para processos de eutrofização.

\section{Material e métodos}

O Lago do IAG (Instituto Astronômico e Geofísico) (2339'03,4”' S e 46³7’26,7’ W) situa-se no Parque Estadual das Fontes do Ipiranga (PEFI), unidade de conservação constituída por remanescente de Mata Atlântica circunscrita em região densamente urbanizada da cidade de São Paulo. É um reservatório urbano raso e pequeno $\left(Z_{\text {máx }}=4,7 \mathrm{~m} ; Z_{\text {med }}=\right.$ $1,51 \mathrm{~m}$; área $=11.270 \mathrm{~m}^{2}$ ), sendo o único oligotrófico dentro da unidade de conservação e, assim, constituindo-se em um sistema de referência (Bicudo et al. 2002a, b).

$\mathrm{Na}$ região litorânea da represa, foram instalados substratos difusores de nutrientes (SDN). Cada unidade experimental (SDN) foi constituída de copo plástico de poliestireno atóxico $(330 \mathrm{~mL})$ preenchida com solução agar $2 \%$ e nutriente, sendo a abertura do copo revestida com malha de náilon de monofilamento $(20 \mu \mathrm{m})$ para permitir a difusão de sais e a colonização do perifíton, conforme Fermino et al. (2004). Três tratamentos foram estabelecidos: controle (sem enriquecimento) e dois níveis de enriquecimento por fósforo $\left(\mathrm{P}_{1}\right.$ e $\left.\mathrm{P}_{2}\right)$. No tratamento $\mathrm{P}_{1}$ adicionou-se, em cada SDN, 4,48 g de fosfato monobásico de potássio $\left(\mathrm{KH}_{2} \mathrm{PO}_{4}\right)$ em $0,33 \mathrm{~L}$ de solução agar $2 \%\left(\mathrm{P}_{1}=15 \mu \mathrm{g} \mathrm{L}^{-1}=0,1 \mathrm{M}\right)$ e no tratamento $\mathrm{P}_{2}, 24,4 \mathrm{~g}\left(\mathrm{P}_{2}=68 \mu \mathrm{g} \mathrm{L}-1=0,5 \mathrm{M}\right)$. Cada tratamento foi composto por 50 unidades experimentais alocadas pela base em tablados de madeira naval submersos e fixos por cavaletes presos ao sedimento. Para a instalação dos tratamentos em campo considerou-se o sombreamento, o sentido da corrente no reservatório e a passagem do barco. O período experimental abrangeu 30 dias (1-31/08/2002), durante os quais foram realizadas coletas matutinas com tempo de colonização de 15, 20, 25 e 30 dias.

Os dados climatológicos foram fornecidos pela Estação Meteorológica do Instituto Astronômico e Geofísico da Universidade São Paulo, câmpus da Água Funda, que dista cerca de $200 \mathrm{~m}$ do local de estudo. As variáveis analisadas foram: irradiação solar, precipitação pluvial, temperatura do ar e velocidade do vento.

Coletas de água para determinação das variáveis limnológicas abióticas foram feitas na sub-superfície com garrafas de polietileno, sendo transportadas em caixas de isopor sob refrigeração. As variáveis limnológicas analisadas foram: radiação subaquática (quantômetro Li-cor, modelo LI-205), temperatura, condutividade elétrica (condutivímetro Digimed), alcalinidade (Golterman \& Clymo 1971), oxigênio 
dissolvido (Golterman et al. 1978), pH (potenciômetro Jenway), formas de carbono inorgânico dissolvido, nitrito $\left(\mathrm{N}-\mathrm{NO}_{2}\right)$ e nitrato $\left(\mathrm{N}-\mathrm{NO}_{3}\right)$ (Mackereth et al. 1978), nitrogênio amoniacal $\left(\mathrm{N}-\mathrm{NH}_{4}\right)$ (Solorzano 1969), ortofosfato $\left(\mathrm{P}-\mathrm{PO}_{4}\right)$ e fósforo total dissolvido (PDT) (Strickland \& Parsons 1965), nitrogênio (NT) e fósforo total (PT) (Valderrama 1981) e sílica solúvel reativa (Golterman et al. 1978). As duas primeiras variáveis foram analisadas em campo. As amostras para a fração dissolvida dos nutrientes foram filtradas em filtro $\mathrm{GF} / \mathrm{F}$ pré-calcinado, sob baixa pressão $(<0,5 \mathrm{~atm})$. As análises foram processadas nos dias de coleta, exceto a fósforo total e nitrogênio total, que foram armazenadas em freezer $\left(-20^{\circ} \mathrm{C}\right)$ e analisadas após dois meses.

A amostragem do perifíton sobre as malhas de náilon seguiu critério aleatório, mediante sorteio dos SDNs. As amostras foram acondicionadas em frascos Wheaton e transportadas em caixas de isopor com gelo e ausência de luz. O material perifítico foi removido do substrato por meio de raspagem com escova de cerdas macias. Foram analisados os seguintes atributos da comunidade perifítica: clorofila-a (Marker et al. 1980, Sartory \& Grobbelaar 1984), massa seca e massa orgânica (APHA 1989), conteúdo de nitrogênio total (Umbreit et al. 1964), conteúdo de fósforo total (Andersen 1976, Pompêo \& Moschini-Carlos 2003) e densidade algal (Ros 1979, adaptado para área do substrato). Todas as análises biológicas foram feitas a partir de três unidades amostrais $(n=3)$, exceto à densidade de algas $(n=2)$. Para análise qualitativa, as amostras foram fixadas com solução de formalina 4\%. Especificamente para as diatomáceas, as amostras foram oxidadas, sendo posteriormente montadas em lâminas permanentes com meio de inclusão Hyrax (Hasle \& Fryxell 1970). Para análise quantitativa, as amostras foram fixadas em solução de lugol acético $0,5 \%$ e a quantificação feita conforme Utermöhl (1958) em microscópio invertido (Zeiss Jena-Sedival 400x). O limite de contagem foi estabelecido de acordo com curva de rarefação de espécies e até atingir o total de 100 indivíduos da espécie mais comum (Bicudo 1990). O biovolume algal foi obtido pela multiplicação da densidade de cada espécie pelo volume médio de suas células considerando, sempre que possível, a dimensão média de 20 indivíduos de cada espécie (Hillebrand et al. 1999, Sun \& Liu 2003). Com base na densidade dos táxons foram determinados os índices de diversidade de Shannon-Wiener (bits ind ${ }^{-1}$ ), dominância, equitatividade e riqueza de espécies (Krebs 1999).

A avaliação do estado nutricional do perifíton baseou-se na determinação de seu conteúdo de nitrogênio e fósforo, adotando-se os limiares de limitação de $5 \%$ e $0,5 \%$ por unidade de massa seca, respectivamente para o nitrogênio e o fósforo (Biggs 1995), bem como a razão N/P (Borchardt 1996).

Os dados quantitativos foram inicialmente submetidos a análise descritiva univariada e exploratória. Como medidas de tendência central utilizou-se média aritmética e mediana e como medidas de dispersão, os quartis, erro padrão e coeficiente de variação de Pearson. Para análise inferêncial aplicou-se análise de variância (ANOVA-1 fator) para a comparação das variáveis entre tratamentos. Para comparação de médias e determinação da diferença mínima significativa utilizou-se o teste de comparação múltipla de Tukey. A análise conjunta das espécies abundantes $(>5 \%$ da densidade média) foi realizada a partir da análise de componentes principais (ACP) com matrizes de covariância e dados transformados pelo $\log (\mathrm{x}+1)$. Os programas estatísticos utilizados foram FITOPAC (Shepherd 1996) para transformação dos dados, PC-ORD (McCune \& Mefford 1999) e MINITAB 14.0.

\section{Resultados}

Variáveis climatológicas e limnológicas abióticas A precipitação pluviométrica foi baixa, variando de 0-19 $\mathrm{mm}(\overline{\mathrm{X}}=2, \mathrm{SE}=0,8)$, assim como a velocidade do vento, que variou de 1 a $3 \mathrm{~m} \mathrm{~s}^{-1}(\overline{\mathrm{X}}=2, \mathrm{SE}=0,1)$. A temperatura do ar oscilou de $15-22{ }^{\circ} \mathrm{C}(\overline{\mathrm{X}}=9, \mathrm{SE}=0,3$, $\mathrm{CV}=9 \%)$ e a irradiação solar variou pouco, de 5 a $17 \mathrm{MJ} \mathrm{m}^{-2}(\overline{\mathrm{X}}=13, \mathrm{SE}=0,65, \mathrm{CV}=29 \%)$.

O resumo das variáveis limnológicas abióticas e da clorofila-a do fitoplâncton da água circundante de cada tratamento encontra-se na tabela 1.

A temperatura da água foi bastante uniforme durante o período de amostragem, tendo amplitude de variação de apenas $0,5^{\circ} \mathrm{C}$. As variáveis radiação subaquática, condutividade, oxigênio dissolvido, formas de carbono inorgânico, alcalinidade e pH não apresentaram diferenças significativas entre tratamentos.

Em relação à concentração de nutrientes totais e dissolvidos, também não houve diferença estatisticamente significativa entre tratamentos (tabela 1). Destaca-se que as concentrações de ortofosfato e PDT foram baixas em todos os tratamentos durante todo o período experimental $\left(<5,0 \mu \mathrm{g} \mathrm{P} \mathrm{L}^{-1}\right)$, enquanto as de $\mathrm{PT}$ foram bastante elevadas para um sistema oligotrófico $\left(>90 \mu \mathrm{g} \mathrm{P} \mathrm{L}^{-1}\right)$. As formas de nitrogênio, concentração de nitrito e de nitrato estiveram abaixo do nível de detecção do método, exceto nitrato, no $15^{\circ}$ dia. As concentrações de $\mathrm{N}$-amoniacal também não foram significativamente diferentes, apresentando baixos coeficientes de variação (controle $=$ $13 \%, \mathrm{P}_{1}=9 \%, \mathrm{P}_{2}=12 \%$ ), o mesmo ocorrendo para NT (controle $=16 \%, \mathrm{P}_{1}=19 \%, \mathrm{P}_{2}=13 \%$ ). A sílica solúvel reativa apresentou pequena flutuação temporal em todos os tratamentos, tendo valores médios e máximos praticamente iguais.

A razão molar N:P da água não apresentou diferença significativa entre tratamentos, indicando a ausência de influência da liberação de fósforo dos tratamentos $\mathrm{P}_{1}$ e $\mathrm{P}_{2}$. Entretanto, verificou-se redução de seus valores médios nos tratamentos com liberação de P. 
Tabela 1. Amplitude de variação e, entre parênteses, média e erro padrão $(n=4)$ das variáveis limnológicas no controle e nos tratamentos enriquecidos por fósforo $\left(\mathrm{P}_{1}: 0,1 \mathrm{M} ; \mathrm{P}_{2}: 0,5 \mathrm{M}\right)$. Última coluna refere-se ao resultado da ANOVA - 1 fator $(\alpha=0,05)$.

Table 1. Limnological parameter ranges and, in between parenthesis, mean and standard error $(n=4)$ in the control and P-enriched treatments $\left(\mathrm{P}_{1}: 0.1 \mathrm{M} ; \mathrm{P}_{2}: 0.5 \mathrm{M}\right)$. Last column refers to one-way ANOVA results $(\alpha=0.05)$.

\begin{tabular}{|c|c|c|c|c|}
\hline Variáveis & Controle & $\mathrm{P}_{1}$ & $\mathrm{P}_{2}$ & ANOVA \\
\hline Temperatura da água $\left({ }^{\circ} \mathrm{C}\right)$ & $\begin{array}{l}19,0-19,3 \\
(19,1)\end{array}$ & $\begin{array}{l}19,0-19,3 \\
(19,1)\end{array}$ & $\begin{array}{l}19,0-19,3 \\
(19,1)\end{array}$ & - \\
\hline $\begin{array}{l}\text { Radiação subaquática } \\
\left(\mu \mathrm{mol} \mathrm{s} \mathrm{s}^{-1} \mathrm{~m}^{-2}\right)\end{array}$ & $\begin{array}{l}61-117 \\
(91 \pm 12)\end{array}$ & $\begin{array}{l}76-108 \\
(94 \pm 7)\end{array}$ & $\begin{array}{l}87-198 \\
(140 \pm 25)\end{array}$ & $\begin{array}{l}\mathrm{F}=0,03 \\
P=0,968\end{array}$ \\
\hline $\begin{array}{l}\text { Condutividade elétrica } \\
\left(\mu \mathrm{S} \mathrm{cm}^{-1}\right)\end{array}$ & $\begin{array}{l}30,70-42,60 \\
(34,7 \pm 5,04)\end{array}$ & $\begin{array}{l}29,10-41,80 \\
(35,08 \pm 6,72)\end{array}$ & $\begin{array}{l}28,90-42,30 \\
(33,25 \pm 6,24)\end{array}$ & $\begin{array}{l}\mathrm{F}=0,36 \\
P=0,704\end{array}$ \\
\hline Alcalinidade $\left(\mathrm{mEq} \mathrm{L}^{-1}\right)$ & $\begin{array}{l}0,06-0,12 \\
(0,10 \pm 0,03)\end{array}$ & $\begin{array}{l}0,06-0,12 \\
(0,10 \pm 0,03)\end{array}$ & $\begin{array}{l}0,06-0,11 \\
(0,10 \pm 0,03)\end{array}$ & $\begin{array}{l}\mathrm{F}=0,00 \\
P=0,996\end{array}$ \\
\hline Oxigênio dissolvido $\left(\mathrm{mg} \mathrm{L}^{-1}\right)$ & $\begin{array}{l}8,00-8,70 \\
(8,35 \pm 0,31)\end{array}$ & $\begin{array}{l}7,90-8,80 \\
(8,38 \pm 0,40)\end{array}$ & $\begin{array}{l}8,00-8,60 \\
(8,30 \pm 0,26)\end{array}$ & $\begin{array}{l}\mathrm{F}=0,05 \\
P=0,948\end{array}$ \\
\hline $\mathrm{CO}_{2}$ livre $\left(\mathrm{mg} \mathrm{L}^{-1}\right)$ & $\begin{array}{l}3,68-5,57 \\
(4,50 \pm 0,82)\end{array}$ & $\begin{array}{l}4,14-5,36 \\
(4,91 \pm 0,54)\end{array}$ & $\begin{array}{l}4,37-5,85 \\
(5,19 \pm 0,69)\end{array}$ & $\begin{array}{l}\mathrm{F}=1,01 \\
P=0,403\end{array}$ \\
\hline $\mathrm{HCO}_{3}\left(\mathrm{mg} \mathrm{L}^{-1}\right)$ & $\begin{array}{l}3,39-7,31 \\
(6,14 \pm 1,86)\end{array}$ & $\begin{array}{l}3,48-7,27 \\
(6,13 \pm 1,78)\end{array}$ & $\begin{array}{l}3,76-6,97 \\
(6,04 \pm 1,53)\end{array}$ & $\begin{array}{l}\mathrm{F}=0,00 \\
P=0,996\end{array}$ \\
\hline $\mathrm{pH}$ & $\begin{array}{l}6,24-6,56 \\
(6,43 \pm 0,15)\end{array}$ & $\begin{array}{l}6,20-6,43 \\
(6,36 \pm 0,11)\end{array}$ & $\begin{array}{l}6,22-6,41 \\
(6,34 \pm 0,08)\end{array}$ & $\begin{array}{l}\mathrm{F}=0,46 \\
P=0,647\end{array}$ \\
\hline $\mathrm{N}-\mathrm{NO}_{3}\left(\mu \mathrm{g} \mathrm{L}^{-1}\right)$ & $\begin{array}{l}6,16-42,81 \\
(20,66 \pm 17,52)\end{array}$ & $\begin{array}{l}1,05-40,49 \\
(11,72 \pm 19,20)\end{array}$ & $\begin{array}{l}0,59-42,58 \\
(12,01 \pm 20,40)\end{array}$ & $\begin{array}{l}\mathrm{F}=8,81 \\
P=0,760\end{array}$ \\
\hline $\mathrm{N}^{-\mathrm{NH}_{4}}\left(\mu \mathrm{g} \mathrm{L}^{-1}\right)$ & $\begin{array}{l}25,40-35,16 \\
(30,31 \pm 3,98)\end{array}$ & $\begin{array}{l}20,25-24,32 \\
(21,81 \pm 1,96)\end{array}$ & $\begin{array}{l}20,25-27,03 \\
(23,57 \pm 2,78)\end{array}$ & $\begin{array}{l}\mathrm{F}=8,81 \\
P=0,080\end{array}$ \\
\hline $\mathrm{NT}\left(\mu \mathrm{g} \mathrm{L}^{-1}\right)$ & $\begin{array}{l}539,39-777,91 \\
(671,41 \pm 124,72)\end{array}$ & $\begin{array}{l}513,33-748,89 \\
(667,60 \pm 111,18)\end{array}$ & $\begin{array}{l}548,50-721,14 \\
(657,91 \pm 82,17)\end{array}$ & $\begin{array}{l}\mathrm{F}=0,02 \\
P=0,983\end{array}$ \\
\hline $\mathrm{P}_{-} \mathrm{PO}_{4}\left(\mu \mathrm{g} \mathrm{L}^{-1}\right)$ & $\begin{array}{l}1,63-3,17 \\
(2,25 \pm 0,4)\end{array}$ & $\begin{array}{l}1,70-3,31 \\
(2,20 \pm 0,4)\end{array}$ & $\begin{array}{l}1,70-2,60 \\
(2,1 \pm 0,3)\end{array}$ & $\begin{array}{l}\mathrm{F}=2,94 \\
P=0,104\end{array}$ \\
\hline $\operatorname{PDT}\left(\mu \mathrm{g} \mathrm{L}^{-1}\right)$ & $\begin{array}{l}1,24-2,85 \\
(2,06 \pm 0,4)\end{array}$ & $\begin{array}{l}1,68-2,93 \\
(2,50 \pm 0,32)\end{array}$ & $\begin{array}{l}2,3-3,59 \\
(2,93 \pm 0,54)\end{array}$ & $\begin{array}{l}\mathrm{F}=2,24 \\
P=0,162\end{array}$ \\
\hline $\mathrm{PT}\left(\mu \mathrm{g} \mathrm{L}^{-1}\right)$ & $\begin{array}{l}96,27-102,72 \\
(100,20 \pm 1,44)\end{array}$ & $\begin{array}{l}103,93-321,64 \\
(186,28 \pm 19,5)\end{array}$ & $\begin{array}{l}109,17-402,27 \\
(262,6 \pm 19,3)\end{array}$ & $\begin{array}{l}\mathrm{F}=2,36 \\
P=0,150\end{array}$ \\
\hline Sílica solúvel reativa $\left(\mathrm{mg} \mathrm{L}^{-1}\right)$ & $\begin{array}{l}2,42-3,03 \\
(2,73 \pm 0,27)\end{array}$ & $\begin{array}{l}2,49-3,02 \\
(2,73 \pm 0,23)\end{array}$ & $\begin{array}{l}2,47-3,02 \\
(2,75 \pm 0,22)\end{array}$ & $\begin{array}{l}\mathrm{F}=0,01 \\
P=0,985\end{array}$ \\
\hline Razão molar N:P inorgânica & $\begin{array}{l}15-28 \\
(21 \pm 7)\end{array}$ & $\begin{array}{l}13-26 \\
(16 \pm 6)\end{array}$ & $\begin{array}{l}13-27 \\
(17 \pm 7)\end{array}$ & $\begin{array}{l}\mathrm{F}=0,53 \\
P=0,607\end{array}$ \\
\hline
\end{tabular}

Estado nutricional do perifíton - Durante todo o período experimental, o perifíton apresentou o maior conteúdo de $\mathrm{P}$ nos tratamentos $\mathrm{P}_{1}$ e $\mathrm{P}_{2}$ (figura $1 \mathrm{~A}$ ), com valores médios 16 e 23 vezes mais elevados do que no controle, respectivamente (controle $=0,3 \% \mathrm{P} ; \mathrm{P}_{1}=5,2 \% \mathrm{P}$;
$\mathrm{P}_{2}=7,1 \% \mathrm{P}$ ). Após 30 dias de colonização, o conteúdo de $\mathrm{P}$ foi significativamente diferente entre tratamentos (F $=29,52 ; P=0,001)$. O conteúdo de $\mathrm{N}$ apresentou pequena variabilidade temporal e entre tratamentos (controle $=3,4 \% \mathrm{~N} ; \mathrm{P}_{1}=3,4 \% \mathrm{~N} ; \mathrm{P}_{2}=3,1 \% \mathrm{~N}$ ) (figura 

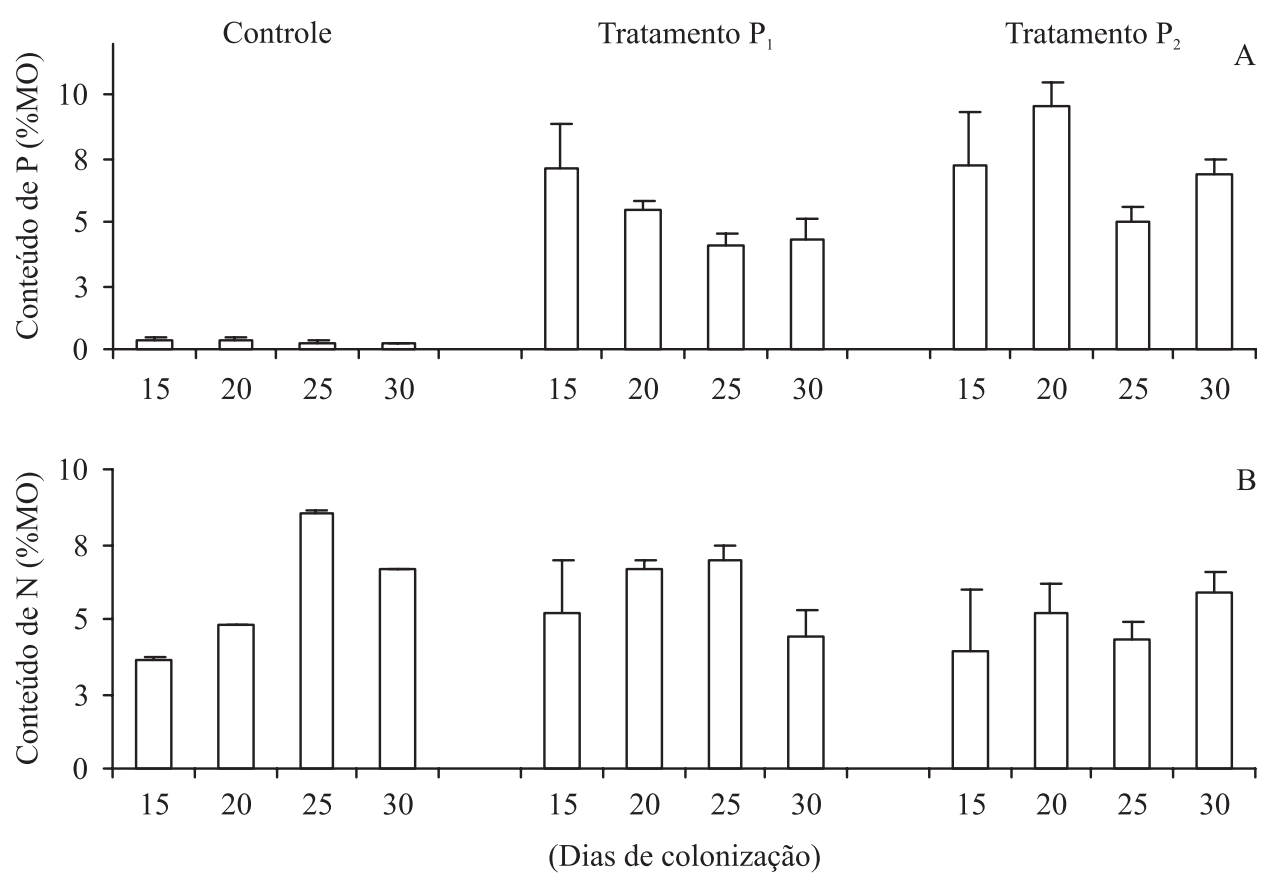

Figura 1. Variação temporal média do conteúdo de fósforo $(\% \mathrm{P})$ e nitrogênio $(\% \mathrm{~N})$ do perifíton $(n=3, \mathrm{SE})$ em três tratamentos durante o período experimental (Controle; Tratamento $\mathrm{P}_{1}$; Tratamento $\mathrm{P}_{2}$ ).

Figure 1. Mean temporal variation of periphyton elemental composition $(\% \mathrm{P}, \% \mathrm{~N})(n=3, \mathrm{SE})$ in the three treatments over the experiment (Control; Treatment $\mathrm{P}_{1}$; Treatment $\mathrm{P}_{2}$ ).

1B), não havendo diferença significativa após 30 dias $(\mathrm{F}=0,67 ; P=0,546)$.

O conteúdo de fósforo do perifíton indicou limitação por $\mathrm{P}$ apenas no controle, enquanto o conteúdo de $\mathrm{N}$ evidenciou ausência de limitação por nitrogênio em todos os tratamentos (figura 2). A razão molar N:P do perifíton também indicou P-limitação no controle, sendo observado $\mathrm{N}$-limitação nos tratamentos $\mathrm{P}_{1}$ e $\mathrm{P}_{2}$ (figura 3). A razão molar N:P da água circundante aos

Figura 2. Gráficos de caixas esquemáticas do conteúdo de nitrogênio (A) e fósforo (B) do perifíton (mediana, quartis, $n=4$; círculo preto $=$ valor médio) durante o período experimental nos tratamentos (Controle; tratamento $\mathrm{P}_{1}$; tratamento $\left.\mathrm{P}_{2}\right)$. Linha pontilhada indica o limiar $(0,5 \%$ para $\mathrm{P}$ e $5 \%$ para $\mathrm{N}$ ), abaixo do qual há limitação por nutriente (Biggs 1995).

Figure 2. Box-plot of nitrogen (A) and phosphorus (B) periphyton contents (medium, quartis, $n=4$; black circle $=$ mean value) in the three treatments during the experiment (Control; Treatment $\mathrm{P}_{1}$; Treatment $\mathrm{P}_{2}$ ). Dashed line indicates threshold values $(0.5 \%$ for $\mathrm{P}$ and $5 \%$ for $\mathrm{N})$, below which nutrient limitation occurs (Biggs 1995).
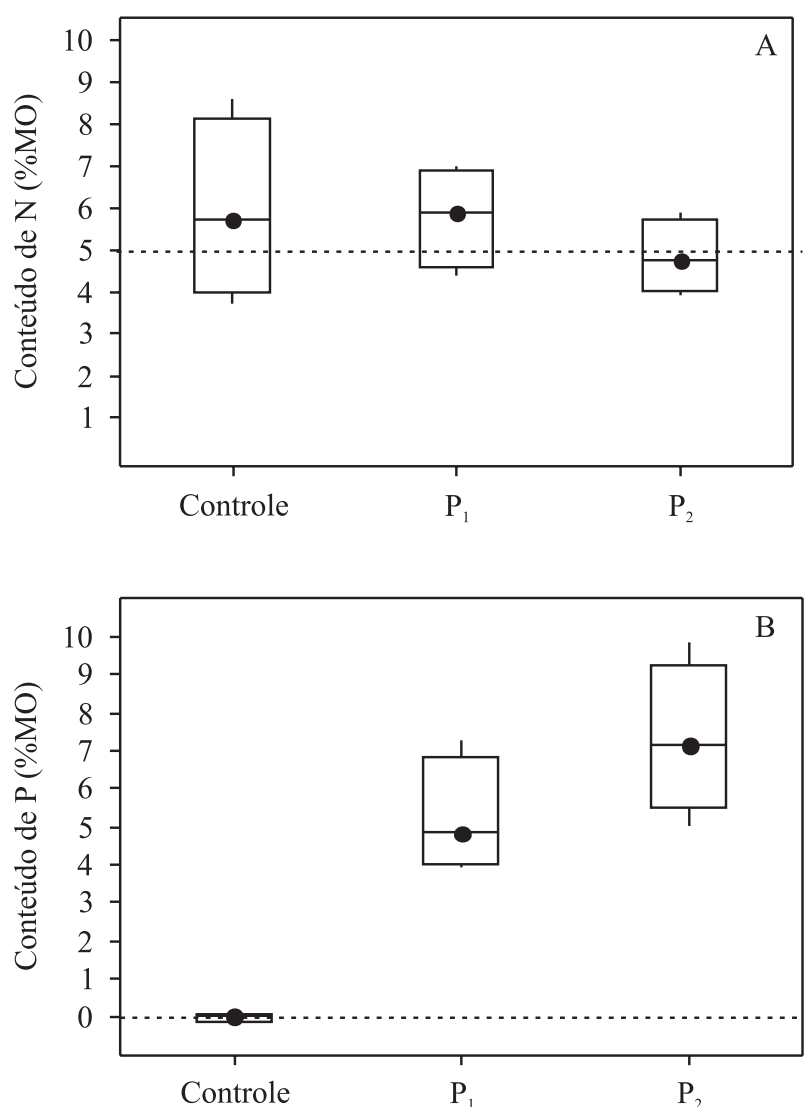


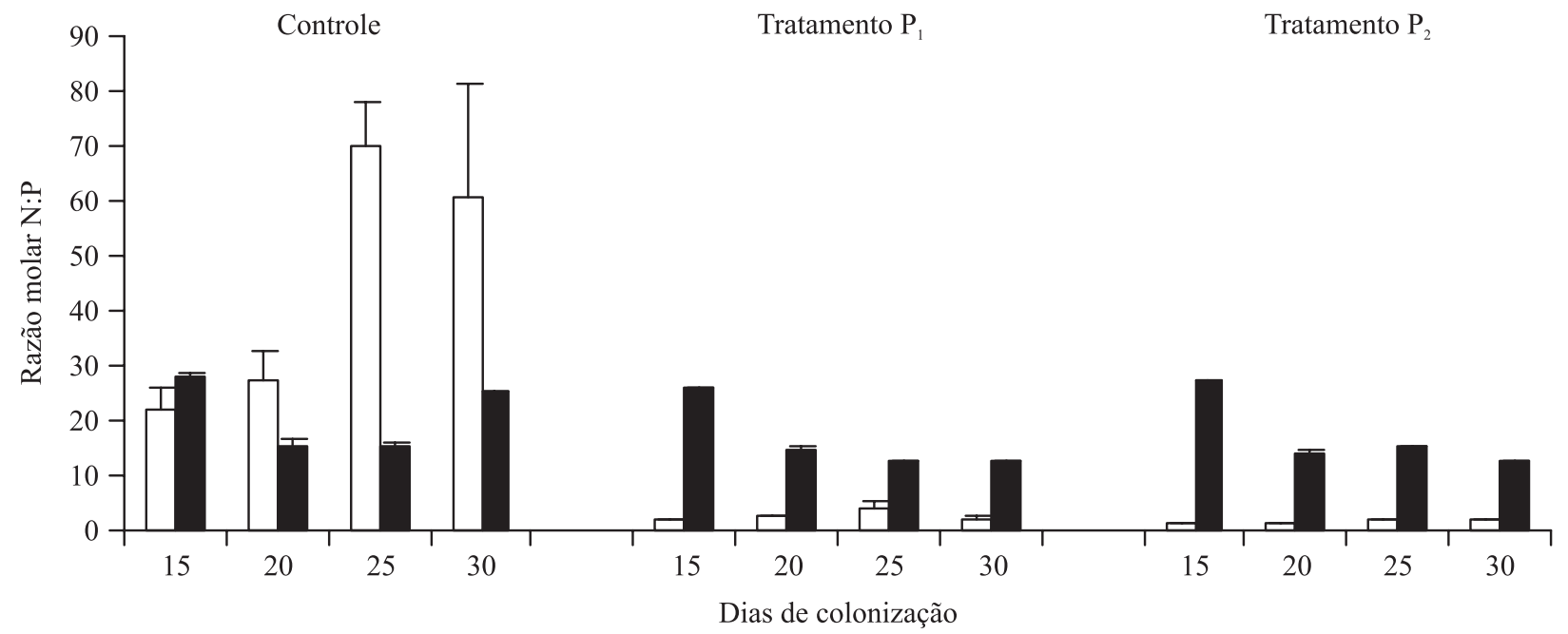

Figura 3. Razão molar N:P média do perifíton $(n=3, \mathrm{SE})$ e dissolvidos na água circundante em três tratamentos durante o período experimental $(\square=$ perifíton; $\boldsymbol{\square}=$ água $)$.

Figure 3. Mean N:P molar ratios of periphyton $(n=3, \mathrm{SE})$ and dissolved in surrounding water of treatments over the experiment ( $\square=$ periphyton; $\mathbf{\square}=$ water).

SDNs evidenciou condições sempre P-limitantes (figura 3). Após 30 dias de colonização, os valores da razão molar N:P do perifíton foram estatisticamente diferentes entre tratamentos $(\mathrm{F}=28,80, P<0,000)$. Em relação ao controle, foram significativamente maiores e iguais nos tratamentos $\mathrm{P}_{1}$ e $\mathrm{P}_{2}$. Já, o conteúdo de $\mathrm{N}$ não apresentou diferença significativa entre tratamentos $(\mathrm{F}=0,67$, $P=0,546)$.

Biomassa do perifíton e densidade de algas - O pico máximo da clorofila-a foi igual em todos os tratamentos $\left(0,4 \mu \mathrm{g} \mathrm{cm}^{-2}\right)$, porém foi atingindo mais rapidamente nos tratamentos $\mathrm{P}_{1}$ e $\mathrm{P}_{2}$ (figura 4A). Em escala temporal, houve decréscimo de biomassa fotossintética após pico máximo, principalmente, nos tratamentos $\mathrm{P}_{1} \mathrm{e} \mathrm{P}_{2}$. Após 30 dias de colonização, os teores de clorofila-a não apresentaram diferença significativa entre tratamentos $(\mathrm{F}=0,60, P=0,578)$. Em relação à massa orgânica do perifíton, o pico máximo praticamente não foi alterado pelo enriquecimento (figura 4B) e após 30 dias de colonização não houve diferença significativa entre tratamentos $(\mathrm{F}=7,28, P=0,071)$.

O biovolume algal médio, em relação ao controle, aumentou 1,5 e 1,3 vez no tratamento $\mathrm{P}_{1}$ e $\mathrm{P}_{2}$, respectivamente (figura $4 \mathrm{C}$ ). Em escala sucessional, apresentou decréscimo nos tratamentos $\mathrm{P}_{1}$ e $\mathrm{P}_{2}$, sendo mais pronunciado no $\mathrm{P}_{2}$. Após 30 dias de colonização, não houve diferença significativa entre tratamentos $(\mathrm{F}=1,88, P=0,296)$.
A densidade total média de algas aumentou com a disponibilidade de fósforo e, em relação ao controle, pico máximo de crescimento foi 2 vezes e 1,4 vez maior no tratamento $\mathrm{P}_{1}$ e $\mathrm{P}_{2}$, respectivamente (figura 4D). Em escala temporal e após pico máximo, houve queda no crescimento algal, particularmente nos tratamento $\mathrm{P}_{1} \mathrm{e}$ $\mathrm{P}_{2}$. Após 30 dias de colonização, não houve diferença significativa entre tratamentos $(\mathrm{F}=1,63, P=0,332)$.

Estrutura do perifíton em nível de classes e espécies algais - Foram identificados 172 táxons, distribuídos em 12 classes e 101 gêneros.

A abundância das classes algais foi alterada com o aumento da disponibilidade de fósforo (figura 5). Com base na densidade, as clorofíceas foram dominantes em todos os tratamentos, dobrando em contribuição mediante enriquecimento. Observou-se, ainda, aumento da densidade de bacilariofíceas em cerca de 3,5 e 2,3 vezes nos tratamentos $P_{1}$ e $P_{2}$, respectivamente. Por outro lado, houve redução de cianofíceas e crisofíceas, particularmente, para a última cuja redução foi de 2,1 e 4,5 vezes nos tratamentos $\mathrm{P}_{1}$ e $\mathrm{P}_{2}$, respectivamente.

Considerando os principais descritores da comunidade perifítica e com base na densidade média para o período sucessional, verificou-se que, no controle, sete espécies contribuíram com mais do que $5 \%$ para estrutura da comunidade, pela ordem decrescente de contribuição: Scenedesmus danubialis Hortobágyi, Pseudanabaena 

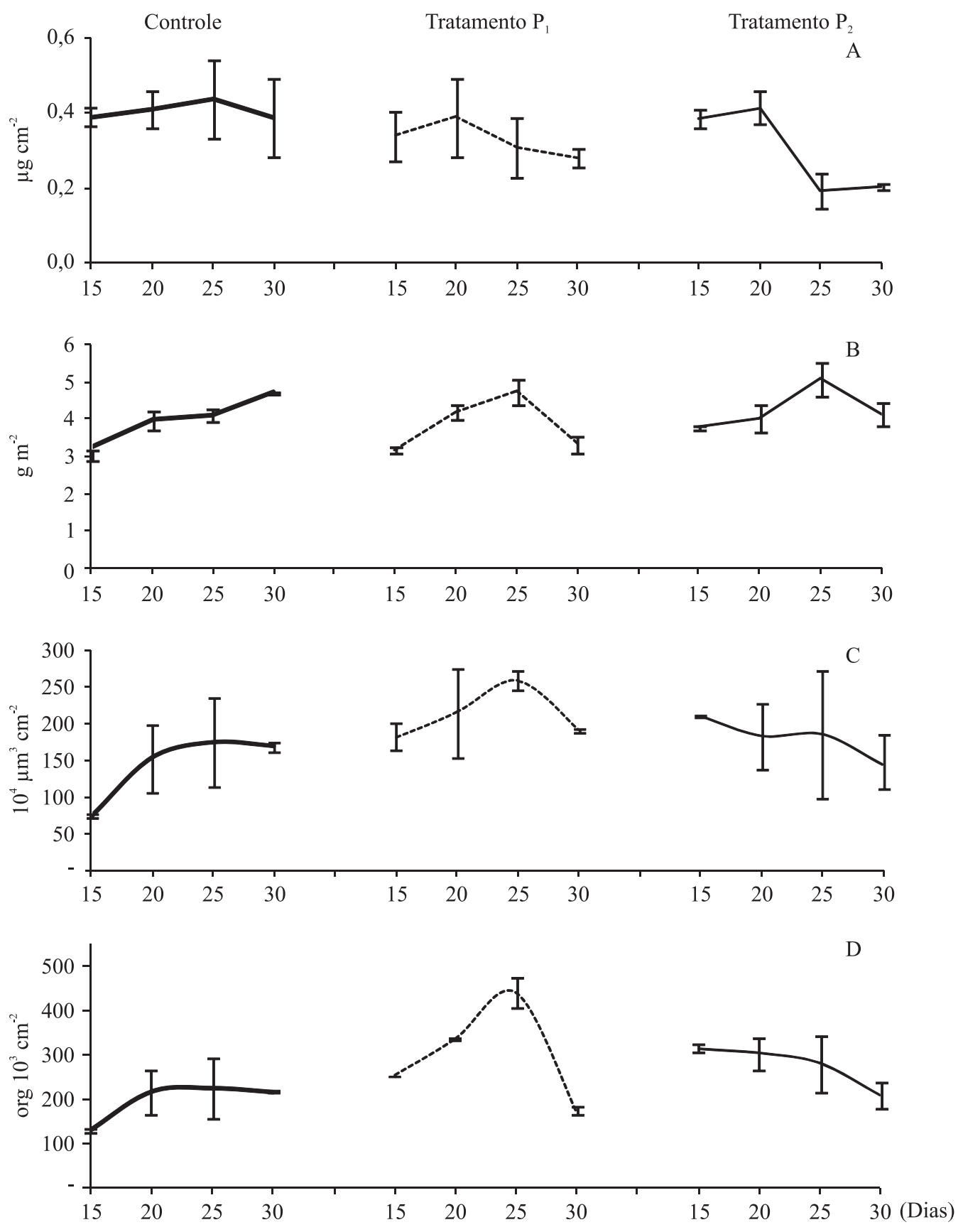

Figura 4. Valores médios de (A) clorofila-a, (B) massa orgânica (MO; $n=3, \mathrm{SE}$ ), (C) biovolume total e (D) densidade algal ( $n=2$, $\mathrm{SD})$ do perifíton nos tratamentos durante o período experimental $\left(-=\right.$ Controle; --- = Tratamento $\mathrm{P}_{1} ;-=$ Tratamento $\left.\mathrm{P}_{2}\right)$.

Figure 4. Periphyton mean values for (A) chlorophyll-a, (B) ash free dry mass (MO; $n=3$, SE), (C) total algal biovolume and (D) total algal density $(n=2, \mathrm{SD})$ in the treatments over the experiment $\left(-=\right.$ Control; $---=$ Treatment $\mathrm{P}_{1} ;-=$ Treatment $\left.\mathrm{P}_{2}\right)$.

galeata Böcher, Scenedesmus ecornis (Ehrenberg) Chodat, Chlamydomonas sordida Ettl, Fluitomonas elliptica Skvortzov ex C. Bicudo, Monoraphidium contortum (Thuret) Komárková-Legnerová e Chromulina elegans Doflein. Nos tratamentos $\mathrm{P}_{1}$ e $\mathrm{P}_{2}$, destacaram-se sete clorofíceas, pela ordem: Monoraphidium contortum, Ankistrodesmus fusiformis Corda sensu Koršikov, Monoraphidium griffithii (Berkeley) KomárkovaLegnerová, Scenedesmus ecornis, Dictyosphaerium pulchellum Wood, Chlamydomonas sordida e 


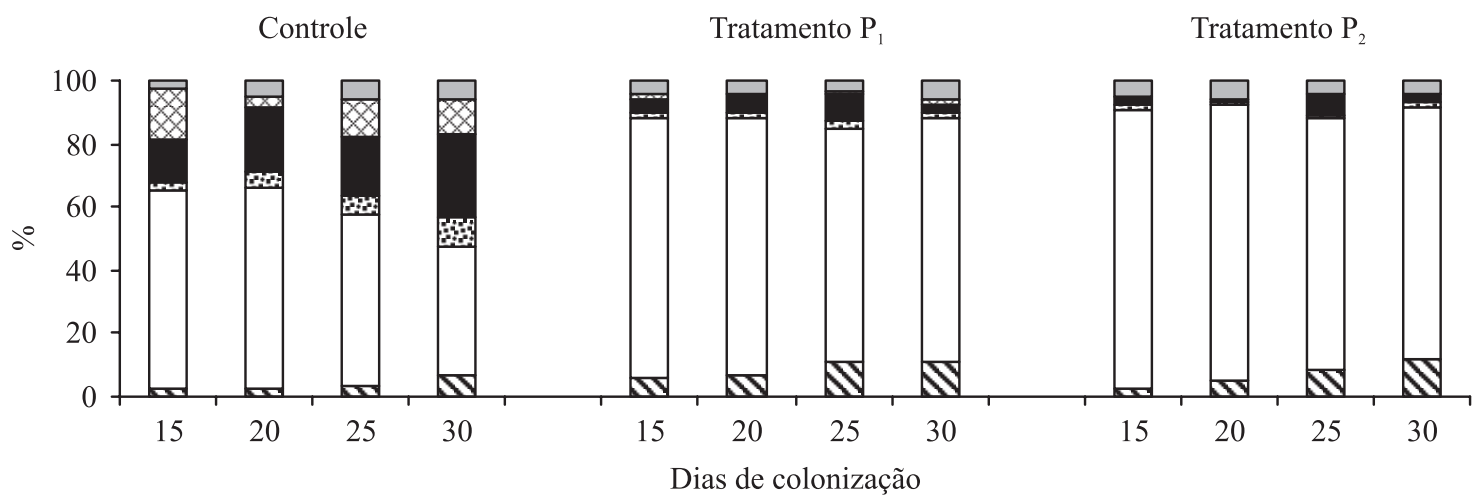

Figura 5. Abundância relativa das classes algais mais representativas no perifíton em três tratamentos durante o período

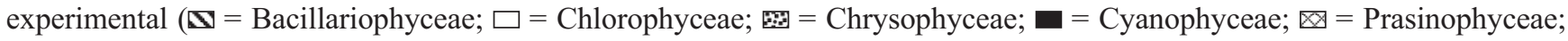
$\square=$ Outras).

Figure 5. Periphyton main algal classes relative abundance in the three treatments over the experiment $(\mathbf{\Sigma}=$ Bacillariophyceae; $\square=$ Chlorophyceae; $\mathrm{a}$ = Chrysophyceae; $\boldsymbol{\square}=$ Cyanophyceae; $\otimes=$ Prasinophyceae; $\square=$ Others).

Scenedesmus danubialis, bem como a diatomácea Nitzschia palea (Kützing) W. Smith.

Dentre as espécies mencionadas, Chromulina elegans e Fluitomonas elliptica tiveram destaque no controle, enquanto Ankistrodesmus fusiformis,
Dictyosphaerium pulchellum, Monoraphidium griffithii, M. contortum e Nitzschia palea, nos tratamentos enriquecidos (figura 6).

A análise de componentes principais (ACP), realizada a partir da densidade de 12 espécies abundantes
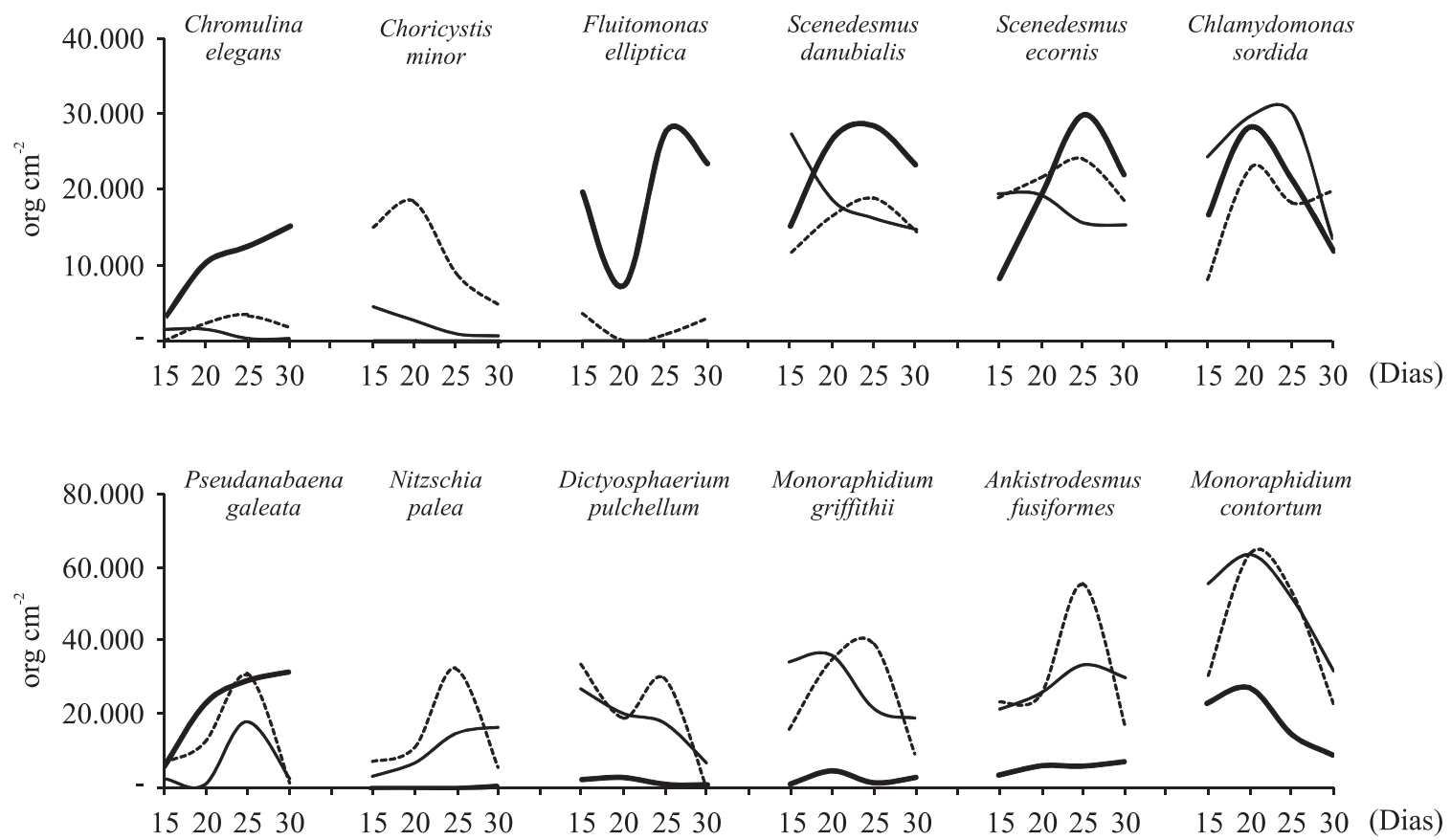

Figura 6. Densidade média $(n=2)$ das espécies de algas perifíticas mais abundantes em cada tipo de tratamento durante o período experimental $\left(-=\right.$ Controle; $---=$ Tratamento $\mathrm{P}_{1} ;-=$ Tratamento $\left.\mathrm{P}_{2}\right)$.

Figure 6. Periphyton mean density $(n=2)$ of most abundant algal species in each treatment over the experiment $(-=$ Control; $---=$ Treatment $\mathrm{P}_{1} ;-=$ Treatment $\mathrm{P}_{2}$ ). 
(contribuição $\geq 5 \%$ da densidade média da comunidade em cada tratamento), resumiu $85 \%$ da variabilidade total dos dados nos dois primeiros eixos (figura 7, tabela 2).

As unidades amostrais dos tratamentos enriquecidos foram ordenadas no lado negativo do eixo $1 \mathrm{e}$ fortemente associadas com as maiores densidades de Monoraphidium griffithii, Choricystis minor (Skuja) Fott, Ankistrodesmus fusiformis, Nitzschia palea, Monoraphidium contortum e Dictyosphaerium pulchellum, que apresentaram elevada correlação $(r \geq 0,8)$ com este eixo (tabela 2). No lado positivo do eixo 1 , foram ordenadas as unidades do controle, as quais se associaram às maiores densidades de Fluitomonas elliptica $(r=0,8)$ e Chromulina elegans $(r=0,5)$. Assim, o eixo 1 representou a mudança da comunidade em nível de espécies em função da disponibilidade de fósforo. Embora com baixa explicabilidade, o eixo 2 evidenciou a separação, em seu lado positivo, das unidades amostrais do tratamento $P_{1}$, associadas às menores densidades de Chlamydomonas sordida e Chromulina elegans e maiores de Fluitomonas elliptica (tabela 2).

Os índices biológicos apresentaram pouca variação entre tratamentos (figuras 8A-D). Os valores médios de diversidade de espécies foram 3,0, 3,3 e 3,1, respectivamente, para o controle, $\mathrm{P}_{1}$ e $\mathrm{P}_{2}$ (figura 8). As maiores mudanças ocorreram no $\mathrm{P}_{1}$, cuja diversidade foi mais elevada em decorrência da diminuição de dominância (figura 8C) e aumento da riqueza (figura 8D).

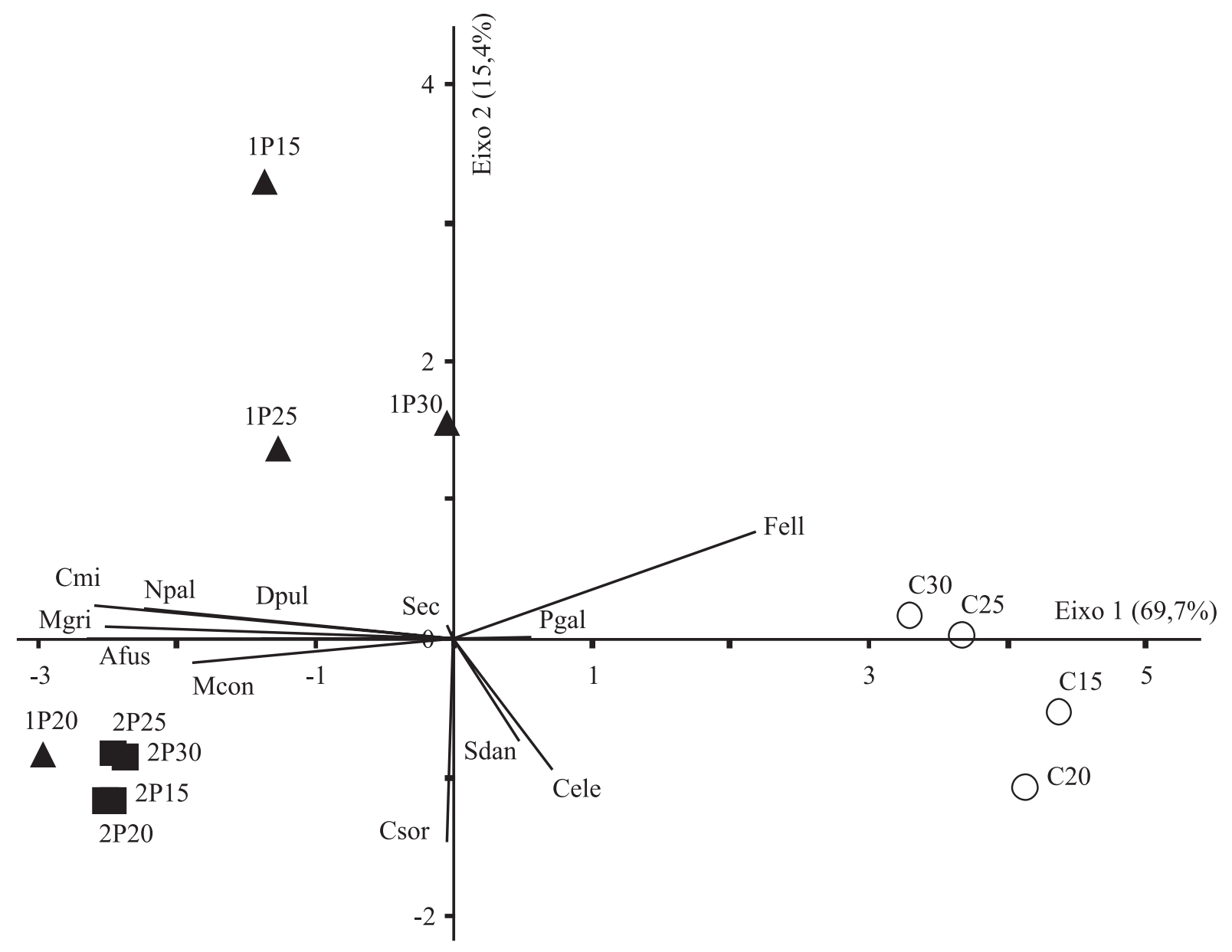

Figura 7. Biplot da ACP para a densidade média das algas perifíticas em três tratamentos durante o período experimental $\left(\mathrm{O}=\mathrm{C}\right.$ : controle; $\boldsymbol{\Lambda}=$ tratamento $\mathrm{P}_{1} ; \boldsymbol{\|}=$ tratamento $\mathrm{P}_{2}$; números indicam os dias de colonização). Abreviação e correlação dos táxons com os eixos, conforme tabela 2.

Figure 7. PCA biplot for periphytic algae mean density in the three treatments over the experiment $(\mathrm{O}=\mathrm{C}: \mathrm{control} ; \mathbf{\Delta}=$ treatment $\mathrm{P}_{1} ; \boldsymbol{\square}=$ treatment $\mathrm{P}_{2}$; numbers immediately after letters represent colonization days). Taxa abbreviations and correlations, according to table 2 . 
Tabela 2. Correlações das espécies de algas perifíticas com os componentes principais 1 e 2 da ACP, com seus respectivos códigos.

Table 2. Periphytic algae species correlation with principal components 1 and 2 of PCA and respective codes.

\begin{tabular}{llcr}
\hline & & \multicolumn{2}{c}{ Componentes Principais } \\
\cline { 3 - 4 } Táxons & & I & II \\
\hline Ankistrodesmus fusiformis & Afus & $-0,917$ & 0,177 \\
Chlamydomonas sordida & Csor & $-0,113$ & $-0,699$ \\
Chromulina elegans & Celeg & 0,500 & $-0,565$ \\
Choricystis minor & Cmi & $-0,929$ & 0,287 \\
Dictyosphaerium pulchellum & Dpul & $-0,682$ & $-0,061$ \\
Fluitomonas elliptica & Fell & 0,855 & 0,507 \\
Monoraphidium contortum & Mcon & $-0,794$ & $-0,239$ \\
Monoraphidium griffithii & Mgri & $-0,941$ & $-0,012$ \\
Nitzschia palea & Npal & $-0,862$ & 0,265 \\
Pseudanabaena galeata & Pgal & 0,432 & 0,088 \\
Desmodesmus danubialis & Sdan & 0,404 & $-0,498$ \\
Scenedesmus ecornis & Seco & $-0,133$ & 0,192 \\
Variação explicada & & $69,7 \%$ & $15,4 \%$ \\
\hline
\end{tabular}
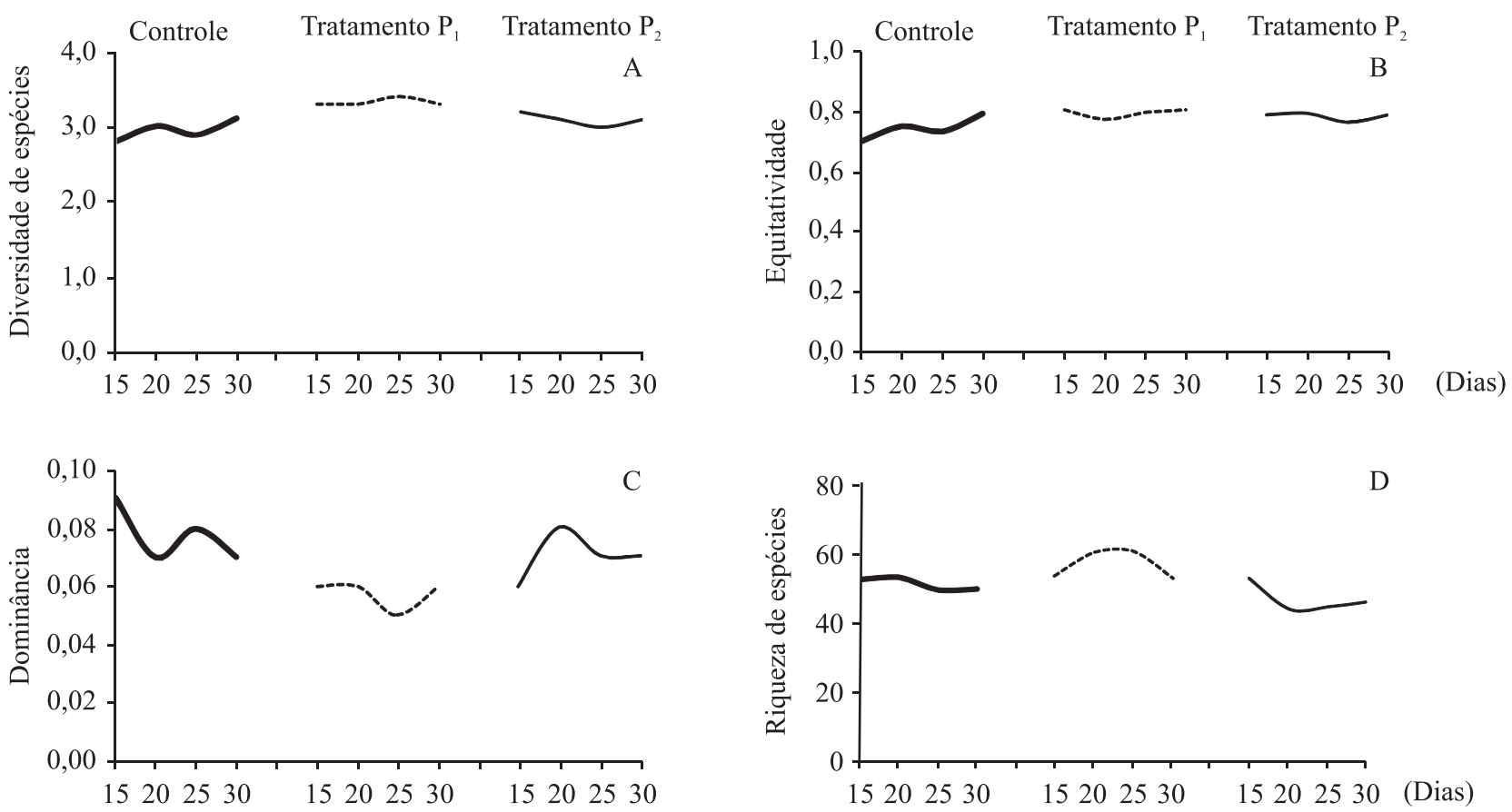

Figura 8. Variação temporal da (A) diversidade de Shannon (bits ind $\left.{ }^{-1}\right)$, (B) equitatividade, (C) dominância e (D) riqueza de espécies da comunidade de algas perifíticas em cada tratamento durante o período experimental $(-=$ Controle; $---=$ Tratamento $\mathrm{P}_{1} ;-=$ Tratamento $\mathrm{P}_{2}$ ).

Figure 8. Temporal variation of (A) Shannon diversity (bits ind $\left.{ }^{-1}\right)$, (B) evenness, (C) dominance index and (D) richness (D) of periphytic algae in each treatment over the experiment $\left(-=\right.$ Control; $---=$ Treatment $\mathrm{P}_{1} ;-=$ Treatment $\left.\mathrm{P}_{2}\right)$. 


\section{Discussão}

Dentre os reservatórios do PEFI, o Lago do IAG é o único com características oligotróficas (Bicudo et al. 2002b). Considerando a disponibilidade de fósforo para o período de 1996 a 1998, a concentração do ortofosfato nas camadas superficiais do sistema sempre esteve abaixo do limite de detecção do método e a de PT, inferior a $20 \mu \mathrm{g} \mathrm{P} \mathrm{L}^{-1}$ (Ferragut 1999, Bicudo et al. 2002b, Lopes et al. 2005, Vercellino \& Bicudo 2006). Entre 2000 e 2001, o reservatório foi esvaziado para obras hidráulicas, completando seu nível somente em 2002. Após este período, a disponibilidade de fósforo aumentou cerca de 10 vezes em relação aos anos anteriores, chegando a $100 \mu \mathrm{g} \mathrm{PT} \mathrm{L}^{-1}$ (dados não publicados). Muito provavelmente, esta mudança deve estar associada a fatores autóctones devido à decomposição da vegetação terrestre inundada desenvolvida sobre o sedimento do sistema.

De modo geral, a liberação de fósforo pelos SDNs no período de 30 dias não foi suficiente para acarretar alterações abióticas na água circundante aos tratamentos, já que nenhuma das variáveis abióticas analisadas apresentou diferença significativa entre tratamentos. Especificamente em relação ao fósforo, observou-se leve tendência de aumento na concentração da água circundante aos tratamentos $\mathrm{P}_{1}$ e $\mathrm{P}_{2}$, evidenciando alguma liberação para água.

A condição limnológica semelhante entre tratamentos deve-se essencialmente ao artefato experimental, uma vez que o fósforo liberado pelos SDNs passa primeiramente pelo biofilme perifítico desenvolvido sobre a malha de monofilamento, antes de se disponibilizar para a água circundante. A difusão do fósforo pelas unidades experimentais foi confirmada pelo estado nutricional do perifíton, cujo conteúdo de fósforo nos tratamentos $\mathrm{P}_{1} \mathrm{e}$ $\mathrm{P}_{2}$ foi significativamente maior do que no controle.

$\mathrm{O}$ conteúdo de nitrogênio e fósforo e a razão $\mathrm{N}: \mathrm{P}$ da massa perifítica têm sido usados com sucesso para indicação do potencial de limitação nutricional do perifíton (Biggs 1995, Borchardt 1996, Hillebrand \& Sommer 1999). Trabalhos mais abrangentes, em escala espacial, utilizaram a o estado nutricional do perifíton para comparar o potencial de limitação algal entre ecossistemas, a exemplo de Maberly et al. (2002) e Francouer et al. (1999), os quais compararam 30 lagos e 12 rios de regiões temperadas, respectivamente.

Em particular para o Lago do IAG, Ferragut (1999) constatou que tais atributos foram decisivos para a identificação do fósforo como nutriente limitante primário. No presente estudo, a razão N:P e o conteúdo de nutrientes da massa perifítica corroboraram tal resultado no controle. Com o aumento da disponibilidade de fósforo nos tratamentos $\mathrm{P}_{1}$ e $\mathrm{P}_{2}$, a comunidade tornou-se $\mathrm{N}$-limitada. Diferentemente, a razão N:P da água indicou condição P-limitante em todos os tratamentos, apesar da alteração estequiométrica entre nitrogênio e fósforo. Tais resultados estão de acordo com Sekar et al. (2002), que reportaram maior concentração de nutrientes no biofilme perifítico do que na água, encontrando razão $\mathrm{N}: \mathrm{P}$ do perifíton sempre menor do que a água devido à bioacumulação de fósforo.

A biomassa fotossintética é uma estimativa amplamente empregada para caracterizar a resposta do perifíton ao aporte de nutrientes em estudos experimentais (e.g. Allen \& Hershey 1996, Zimba 1998) e observacionais (Rodrigues et al. 2005, Vercellino \& Bicudo 2006). No presente, a biomassa fotossintética do perifíton não foi preditiva de mudança da limitação nutricional e do aumento da disponibilidade de fósforo. Muito provavelmente, a disponibilidade deste nutriente na água (96-102 $\mu \mathrm{g} \mathrm{PT} \mathrm{L}^{-1}$ ) tenha promovido produção similar de biomassa entre tratamentos. Comparando o pico máximo da biomassa da comunidade perifítica do Lago do IAG, a produção de biomassa fotossintética em condição sem enriquecimento foi cerca de 14 e 1,4 vezes maior do que o encontrado por Ferragut (1999) e Vercellino \& Bicudo (2006), respectivamente, ambos estudos realizados anteriormente ao esvaziamento da represa. Esses resultados sugerem que o Lago do IAG sofreu mudanças temporais (1996-2002) na região litorânea em relação ao aumento da disponibilidade de fósforo, porém permanecendo em condição P-limitante.

Diferentemente das estimativas de biomassa (clorofila-a, massa orgânica e biovolume), a estrutura em nível de classes taxonômicas da comunidade de algas perifíticas respondeu ao enriquecimento por fósforo, embora não aos diferentes níveis de adição do nutriente. $\mathrm{O}$ grupo algal mais favorecido foi o das clorofíceas, cuja representatividade duplicou nos tratamentos enriquecidos. Experimentalmente, Ferragut (1999) reportou que a alta disponibilidade de fósforo favoreceu a substituição de crisofíceas por clorofíceas no perifíton. Outros estudos também demonstraram o aumento de clorofíceas perifíticas como conseqüência do processo de eutrofização (Jensen et al. 1994, Biggs 1996) e do aporte de fósforo (Havens et al. 1999).

A densidade média das algas perifíticas não apresentou diferença significativa entre tratamentos, contudo, apresentou uma sensibilidade maior do que os demais atributos ao aumento da disponibilidade de P. Em estudo experimental no Lago do IAG, Ferragut (1999) 
encontrou aumento significativo da densidade de algas perifíticas em condição de adição isolada ou combinada de fósforo. Considerando a densidade populacional das descritoras, a participação de Fluitomonas elliptica e Chromulina elegans foi extremamente reduzida nos tratamentos enriquecidos, enquanto Ankistrodesmus fusiformis, Choricystis minor, Dictyosphaerium pulchellum, Monoraphidium contortum, M. griffithii e Nitzschia palea foram beneficiadas. Tais espécies formaram uma guilda indicadora do aumento da disponibilidade de fósforo para a comunidade.

Dentre as clorofíceas, o gênero Monoraphidium é comumente associado a ambiente raso e enriquecido (Reynolds et al. 2002) e, particularmente, M. contortum já foi associada ao perifíton em condições de elevada disponibilidade de fósforo no Lago das Garças (Barcelos 2003) e do IAG (Ferragut 2004). No fitoplâncton, Ankistrodesmus pertence à associação de espécies características de condições eutróficas e hipereutróficas (Reynolds 1984). Trabalhos sobre fitoplâncton relataram, ainda, a ocorrência frequente de Dictyosphaerium pulchellum em sistema eutrófico (Rosen 1981) e seu usual aumento populacional com a eutrofização (Margalef 1983). Choricystis minor foi encontrada com elevada densidade no fitoplâncton do eutrófico Lago das Garças (Tucci 2002).

Nitzschia palea é uma diatomácea bem caracterizada por sua preferência por meios hipereutróficos (Van Dam et al. 1994) e ricos em matéria orgânica (Somashekar 1984). Vários estudos associaram essa espécie no perifíton ao enriquecimento, principalmente por fósforo (Pringle 1990, McCormick \& Stevenson 1998, Winter \& Duthie 2000). Essa espécie também já foi associada no perifíton às condições eutróficas do Lago das Garças no período chuvoso (Vercellino 2001), à elevada disponibilidade de fósforo em condições experimentais no Lago do IAG (Ferragut 2004) e das Ninféias (Fermino 2006), ou seja, sendo bastante comum em condições de maior disponibilidade de fósforo na área de estudo.

Em relação à diversidade da comunidade de algas perifíticas, há trabalhos que reportam diminuição (Carrick et al. 1988, Hillebrand \& Sommer 2000) ou aumento (Pringle 1990) em condições eutróficas. No presente, a diversidade teve suave aumento nos tratamentos enriquecidos por fósforo, o que corrobora o estudo de Vercellino (2001), que comparou a comunidade perifítica de represas eutrófica (Lago das Garças) e oligotrófica (Lago do IAG) no PEFI. Todavia, ainda para a área de estudo, trabalhos experimentais demonstraram aumento da diversidade em condição mesotrófica (Barcelos 2003). Com base nos resultados sobre a comunidade perifítica para os ambientes do PEFI, a diversidade foi considerada pouco sensível às alterações de disponibilidade de nutrientes.

No presente estudo, demonstrou-se a ausência de resposta da biomassa perifítica (clorofila-a, massa orgânica, biovolume algal) e densidade total de algas frente aos níveis de enriquecimento por fósforo. Exceto à massa orgânica, tais resultados discordam de Ferragut (1999), que avaliou o efeito isolado e combinado da adição de fósforo e nitrogênio para o perifíton no Lago do IAG. Muito provavelmente, a maior disponibilidade desse nutriente na água da região litorânea em relação ao período anterior ao esvaziamento da represa (1999) promoveu maior produção de biomassa em condições não enriquecidas. Outro fator que concorreu para os níveis similares de biomassa entre tratamentos foi a limitação do crescimento do perifíton pelo nitrogênio, conforme demonstrado pelo estado nutricional da comunidade (razão molar $\mathrm{N}: \mathrm{P}=2,6$ e 1,2, respectivamente para os tratamentos $\mathrm{P}_{1}$ e $\mathrm{P}_{2}$ ). Entretanto, apesar dos valores mais elevados de fósforo na água, o conteúdo de $\mathrm{P}$ e $\mathrm{N}$, bem como a razão $\mathrm{N}: \mathrm{P}$ da biomassa perifítica, indicaram limitação primária pelo fósforo, corroborando dados de Ferragut (1999).

Apesar da biomassa algal ser usualmente uma fração pequena da massa orgânica perifítica, a mesma apresenta notável influência sobre a razão C:P (Frost et al. 2005). Desta forma, pode-se considerar o estado nutricional do perifíton como uma boa ferramenta na avaliação da disponibilidade de nutrientes do meio, conforme verificado no presente e em outros estudos (e.g. Borchardt 1996, Hillebrand \& Sommer 2000, Huszar et al. 2005).

A estrutura de classes e, particularmente, de espécies da comunidade perifítica forneceu resposta bastante refinada ao enriquecimento por fósforo, embora não ao aumento de sua disponibilidade. Em termos de grandes grupos taxonômicos, as clorofíceas associaram-se intimamente à adição de fósforo, reforçando sua afinidade à maior disponibilidade deste recurso. $\mathrm{O}$ aumento da disponibilidade de fósforo reduziu a participação de duas espécies, favorecendo, principalmente, o desenvolvimento de sete espécies, já estreitamente associadas à disponibilidade de fósforo em outros sistemas lacustres da área de estudo (PEFI), bem como fora do Brasil. A associação dessas espécies pode ser potencialmente bioindicadora do aporte de fósforo para a área de estudo.

Salienta-se a necessidade de se avaliar as causas e, assim, as medidas preventivas de eventual processo de eutrofização da represa. Nesse sentido, a comunidade perifítica respondeu experimentalmente como indicador 
de um processo de enriquecimento, tendo como principais descritores ambientais do aumento da disponibilidade de fósforo o seu estado nutricional $(\mathrm{N}$ e $\mathrm{P})$ e a estrutura em nível de espécies algais. Reforça-se, portanto, o uso do perifíton como mais uma ferramenta para acessar alterações da qualidade ecológica da água, podendo subsidiar propostas de prevenção e recuperação de ecossistemas lacustres tropicais.

Agradecimentos - À Fapesp, Fundação de Amparo à Pesquisa do Estado de São Paulo, pela bolsa de doutorado concedida à primeira autora (Processo no 06953-0) Fapesp e ao CNPq, Conselho Nacional de Desenvolvimento Científico e Tecnológico (Bolsa concedida a DCB, processo 520745/ 96-5).

\section{Referências bibliográficas}

ALLEN, N.S. \& HERSHEY, A.E. 1996. Seasonal changes in chlorophyll a response to nutrient amendments in a north shore tributary of lake Superior. Journal of the North American Benthological Society 15:170-178.

ANDERSEN, J.M. 1976. An ignition method for determination of total phosphorus in lake sediments. Water Research 10:329-331.

AMERICAN PUBLIC HEALTH ASSOCIATION. 1989. Standard methods for the examination of water and waste water. American Public Health Association, 17 ${ }^{\text {th }}$ ed, Washington DC.

BARCELOS, E.M. 2003. Avaliação do perifíton como sensor da oligotrofização experimental em reservatório eutrófico (Lago das Garças, São Paulo). Dissertação de mestrado, Universidade Estadual Paulista, Rio Claro.

BICUDO, C.E.M., CARMO, C.F., BICUDO, D.C., HENRY, R., PIÃO, A.C.S., SANTOS, C.M. \& LOPES, M.R.M. 2002a. Morfologia e morfometria de três reservatórios do PEFI. In Parque Estadual das Fontes do Ipiranga (PEFI): unidade de conservação ameaçada pela urbanização de São Paulo (D.C. Bicudo, M.C. Forti \& C.E.M. Bicudo, eds.). Secretaria do Meio Ambiente do Estado de São Paulo, São Paulo, p.143-160.

BICUDO, D.C. 1990. Considerações sobre metodologias de contagem de algas do perifíton. Acta Limnologica Brasiliensia 3:459-475.

BICUDO, D.C., FORTI, M.C., CARMO, C.F., BOUROTTE, C., BICUDO, C.E.M., MELFI, A.J. \& LUCAS, Y. 2002 b. A atmosfera, as águas superficiais e os reservatórios no PEFI: caracterização química. In Parque Estadual das Fontes do Ipiranga (PEFI): unidade de conservação ameaçada pela urbanização de São Paulo. (D.C. Bicudo, M.C. Forti \& C.E.M. Bicudo, eds.). Secretaria do Meio Ambiente do Estado de São Paulo, São Paulo, p.161-200.
BIGGS, B.J.F. 1995. The contribution of flood disturbance, catchment geology and land use to the habitat template of periphyton in stream ecosystems. Freshwater Biology 33:419-448.

BIGGS, B.J.F. 1996. Patterns in benthic algae of streams. In Algal ecology: freshwater benthic ecosystems. (R.J. Stevenson, M.L. Bothwell \& R.L. Lowe, eds.). Academic Press, San Diego, p.31-56.

BORCHARDT, M.A. 1996. Nutrients. In Algal ecology: freshwater benthic ecosystems. (R.J. Stevenson, M.L. Bothwell \& R.L. Lowe, eds.). Academic Press, San Diego, p.184-227.

BOTHWELL, M.L. 1988. Growth rate responses of lotic periphytic diatoms to experimental phosphorus enrichment: the influence of temperature and light. Canadian Journal Fisheries of Aquatic Science 45: 261-270.

BREZONIK, P.L. \& POLLMAN, C.D.. 1999. Phosphorus chemistry and cyccling in Florida Lakes: global issues and local perspectives. In Phosphorus Biogeochemistry in subtropical ecosystems. (K.R. Reddy, G.A. O'Connor \& C.L. Schelske, eds.). Lewis Publishers, Boca Raton, Florida, p.69-110.

CARRICK, H.J., LOWE, R.L. \& ROTENBERRY, J.T. 1988. Guilds of benthic algae along nutrient gradients: relationship to algal community diversity. Journal of the North American Benthological Society 7:117-128.

CERRAO, G.C., MOSCHINI, V.M., SANTOS M.J. \& RIGOLIN, O. 1991. Efeito do enriquecimento artificial sobre a biomassa do perifíton em tanques artificiais na Represa do Lobo ("Broa"). Revista Brasileira de Biologia 51:71-78.

DENICOLA, D.M., EYTO, E., WEMAERE, A. \& IRVINE, K. 2006. Periphyton response to nutrient addition in 3 lakes of different benthic productivity. Journal of the North American Benthological Society 25:616-631.

DODDS, W.K. 2003. The role periphyton in phosphorus retention in shallow freshwater aquatic systems. Journal of Phycology 39:840-849.

DODDS, W.K. \& PRISCU, J.C. 1990. Mesocosm studies on the influence of phosphate enrichment on ammonium and nitrate flux in a oligotrophic lake. Hydrobiologia 206:235-243.

ENGLE, D.L. \& MELACK, J.M. 1993. Consequences of riverine flooding for seston and the periphyton of floating meadows in a Amazon floodplain lake. Limnology \& Oceanography 38:1500-1520.

FERMINO, F.S. 2006. Avaliação sazonal dos efeitos do enriquecimento por $\mathrm{N}$ e $\mathrm{P}$ sobre o perifíton em represa tropical rasa mesotrófica (Lago das Ninféias, São Paulo). Tese de doutorado, Universidade Estadual Paulista, Rio Claro.

FERMINO, F.S., BICUDO, D.C. \& MERCANTE, C.T. 2004. Substrato difusor de nutrientes (SDN): avaliação do método em laboratório para experimentos in situ com perifíton. Acta Scientiarum 26:273-280. 
FERRAGUT, C. 1999. Efeito do enriquecimento por $\mathrm{N}$ e $P$ sobre a colonização e sucessão da comunidade de algas perifíticas: biomanipulação em reservatório raso oligotrófico de São Paulo. Dissertação de mestrado, Universidade Estadual Paulista, Rio Claro.

FERRAGUT, C. 2004. Respostas das algas perifíticas e planctônicas à manipulação de nutrientes $(\mathrm{N}$ e $\mathrm{P}) \mathrm{em}$ reservatório urbano (Lago do IAG, São Paulo). Tese de doutorado, Universidade Estadual Paulista, Rio Claro.

FRANCOEUR, S.N., BIGGS, B.J.F, SMITH, R.A. \& LOWE, R.L. 1999. Nutrient limitation of algal biomass accrual in streams: seasonal patterns and a comparison of methods. Journal of the North American Benthological Society 18:242-260.

FROST, P.C., HILLEBRAND, H. \& KAHLERT, M. 2005. Low algal carbon content and its effect on the $\mathrm{C}: \mathrm{P}$ stoichiometry of periphyton. Freshwater Biology 50:1781-1785.

GOLTERMAN, H.L. \& CLYMO, R.S. 1971. Methods for chemical analysis of freshwaters. Blackwell Scientific Publications, Oxford.

GOLTERMAN, H.L., CLYMO, R.S., OHMSTAD, M.A.M. 1978. Methods for physical and chemical analysis of freshwaters. Blackwell Scientific Publications, Oxford.

HASLE, G.R. \& FRYXELL, G.A. 1970. Diatoms: cleaning and mouthing for light and electron microscopy. Transactions of the American Microscopical Society 89:469-474.

HAVENS, K.E., EAST, T.L., RODUSKY, A.J. \& SHARFSTEIN, B. 1999. Littoral periphyton responses to nitrogen and phosphorus: an experimental study in a subtropical lake. Aquatic Botany 63:267-290.

HECKY, R.E. \& KILHAM, P. 1988. Nutrient limitation of phytoplankton in freshwater and marine environments. A review of recent evidence on the effects enrichment. Limnology \& Oceanography 33:796-822.

HILL, B.H., HERLHY, A.T., KAUFMANN, P.R, STEVENSON, R.J., MCCORMICK, F.H. \& JOHNSON, C.B. 2000. Use of periphyton assemblage data as an index of biotic integrity. Journal of the North American Benthological Society 19:50-67.

HILLEBRAND, H., DURSELEN, C-D., KIRSCHTEL, D., POLLINGHER, U., ZOHARY, T. 1999. Biovolume calculation for pelagic and benthic microalgae. Journal Phycology 35:403-424.

HILLEBRAND, H. \& SOMMER, U. 1999. The nutrient stoichiometry of benthic microalgae growth: Redfield proportions are optimal. Limnology \& Oceanography 44:440-446.

HILLEBRAND, H. \& SOMMER, U. 2000. Diversity of benthic microalgae in response to colonization time and eutrophication. Aquatic Botany 67:221-223.

HORNER, R.R., WELCH, E.B., SEELEY, M.R. \& JACOB, J.M. 1990. Responses of periphyton changes in current velocity, suspended sediment and concentration phosphorus. Freshwater Biology 24:215-232.
HUSZAR, V.L.M., BICUDO, D.C., GIANI, A., FERRAGUT, C., MARTINELLI, L.A. \& HENRY, R. 2005. Subsídios para compreensão sobre a limitação de nutrientes ao crescimento do fitoplâncton e perifíton em ecossistemas continentais lênticos no Brasil. In Lições em limnologia: fronteiras conceituais (F. Roldam, D. César \& M. Marinho, eds.). RiMa Editora, São Carlos, p.243-260.

JENSEN, J.P., JEPPENSEN, E., OLBRIK, K., KRISTENS, P. 1994. Impact of nutrients and physical factors on shift from cyanobacterial to chlorophyte dominance in shallow Danish lakes. Canadian Journal Fisheries Aquatic Science 51:1692-1699.

KREBS, C.J. 1999. Ecological methodology. Addisson Wesley Longman, Menlo Park.

LOPES, M.R.M., BICUDO, C.E.M. \& FERRAGUT, C. 2005. Short term spatial and temporal variation of phytoplankton in a shallow tropical oligotrophic reservoir, southeast Brazil. Hydrobiologia 542:235-247.

LOWE, R.L. \& PAN, Y. 1996. Benthic algal communities as biological monitors. In Algal ecology: freshwater benthic ecosystems (J.R. Stevenson, M.L. Bothwell \& R.L. Lowe, eds.). Academic Press, San Diego, p.705-739.

MABERLY, S.C., KING, L., DENT, M.M., JONES, R.I. \& GIBSON, C.E. 2002. Nutrient limitation of phytoplankton and periphyton growth in upland lakes. Freshwater Biology 47:2136-2152.

MACKERETH, F.J.H., HERON, J. \& TALLING, J.F. 1978. Water analysis: some revised methods for limnologists. Wilson \& Son, Kendall.

MARGALEF, R. 1983. Limnologia. Omega, Barcelona.

MARKER, A.F.H., NUSCH, H., RAI, H. \& RIEMANN, B. 1980. The measurement of photosynthetic pigments in freshwaters and standardization of methods: conclusion and recommendations. Archiv für Hydrobiologie 14: 91-106.

MCCORMICK, P.V. \& O’DELL, M.B. 1996. Quantifying periphyton responses to phosphorus in the Florida Everglades: a synoptic-experimental approach. Journal of the North American Benthological Society 15:450468.

MCCORMICK, P.V., O’DELL, M.B., SHUFORD III, R.B.E., BACKUS, J.G. \& KENNEDY, W.C. 2001. Periphyton responses to experimental phosphorus enrichment in a subtropical wetland. Aquatic Botany 71:119-139.

MCCORMICK, P.V. \& STEVENSON, R.J. 1998. Periphyton as a tool for ecological assessment and management in the Florida Everglades. Journal of Phycology 34:726733.

MCCUNE, B. \& MEFFORD, M.J. 1999. PC-ORD. Multivariate analysis of ecological data, version 3.0. MjM Software Design, Oregon.

MENDES, R.S. \& BARBOSA, F.A.R. 2002. Efeito do enriquecimento in situ sobre a biomassa da comunidade perifítica de um córrego de altitude da Serra do Cipó (MG). Acta Limnologica Brasiliensia 14:77-86. 
NEWMAN, S., McCORMICK, P.V. \& BACKUR, J.G. 2003. Phosphatase activity as an early warning indicator of wetland eutrophication: problems and prospects. Journal of Applied Phycology 15:45-52.

PAN, Y., STEVENSON, R.J., VAITHIYANATHAN, P., SLATE, J. \& RICHARDSON, C.J. 2000. Changes in algal assemblages along observed and experimental phosphorus gradients in a subtropical wetland, USA. Freshwater Biology 44:339-353.

POMPÊO, M.L.M. \& MOSCHINI-CARLOS, V. 2003. Macrófitas aquáticas e perifíton: aspectos ecológicos e metodológicos. Rima/Fapesp, São Carlos.

PRINGLE, C.M. 1990. Nutrient spatial heterogeneity: effects on community structure, physiognomy, and diversity of stream algae. Ecology 71:905-920.

REYNOLDS, C.S. 1984. The ecology of freshwater phytoplankton. Cambridge University Press, Cambridge.

REYNOLDS, C.S. \& DAVIES, P.S. 2001. Sources and bioavailability of phosphorus fractions in freshwater: a British perspective. Biological Reviews of the Cambridge Philosophical Society 76:27-64.

REYNOLDS, C.S., HUSZAR, V., KRUK, C., NASELLIFLORES, L. \& MELO, S. 2002. Towards a functional classification of the freshwater phytoplankton. Journal of Plankton Research 24:417-428.

RODRIGUES, L., FONSECA, I.A., LEANDRINI, J.A., FELISBERTO, S.A. \& SILVA, E.L.V. 2005. Distribuição espacial da biomassa perifítica em reservatórios e relação com o tipo de substrato. In Biocenoses em reservatórios: padrões espaciais e temporais. (L. Rodrigues, S.M.T. Thomaz, A.A. Agostinho \& L.C. Gomes, eds.). RiMa, São Carlos, p.87-96.

ROS, J. 1979. Prácticas de ecologia. Omega, Barcelona.

ROSEN, G. 1981. Phytoplancton indicators and their relations to certain chemical and physical factors. Limnologica 13:263-296.

SARTORY, D.P. \& GROBBELAAR, J.E. 1984. Extraction of chlorophyll a from freshwater phytoplankton for spectrophotometric analysis. Hydrobiologia 114:177187.

SCHELSKE, C.L. \& STOERMER, E.F. 1971. Eutrophication, silica depletion and predicted changes in algal quality in lake Michigan. Science 173:423-424.

SEKAR, R.,NAIR,K.V.K., RAO, V.N.R.\&VENUGOPALAN, V.P. 2002. Nutrient dynamics and successional changes in a lentic freshwater biofilm. Freshwater Biology 47:1893-1907.

SHEPHERD, G.J. 1996. FITOPAC 1: manual do usuário. Unicamp, Campinas.

SOLORZANO, L. 1969. Determination of ammonia in natural waters by the phenolhypochlorite method. Limnology \& Oceanography 14:799-801.
SOMASHEKAR, K. 1984. Phytoplankton constituents as indicator of water quality: a study of the river Cauvery. International Journal Environmental Studies 23:209215.

STRICKLAND, J.D. \& PARSONS, T.R. 1965. A manual of sea water analysis. Bulletin of the Fisheries Research Board of Canada, 125p.

SUN, J. \& LIU, D. 2003. Geometric models for calculating cell biovolume and surface area for phytoplankton. Journal Plankton Research 25:1331-1346.

TUCCI, A. 2002. Sucessão da comunidade fitoplanctônica de um reservatório urbano e eutrófico, São Paulo, SP, Brasil. Tese de doutorado, Universidade Estadual Paulista, Rio Claro.

UMBREIT, W.W., BURRIS, R.H. \& STAUFFER, J.F. 1964. Manometric methods applicable to the study of tissue metabolism. Burgess Publishing Co, Minneapolis.

UTERMÖHL, H. 1958. Zur Vervolkomnung der quantitative Phytoplankton: Methodik. Mitteillung Internationale Vereinigung Theoretische Angewandte Limnologie 9:1-38.

VALDERRAMA, G.C. 1981. The simultaneous analysis of total nitrogen and total phosphorus in natural waters. Marine Chemical 10:109-122.

VAN DAM, H., MERTENS, A. \& SINKILDAM, J. 1994. A coded checklist and ecological indicator values of freshwater diatoms from the Netherlands. Journal of Aquatic Ecology 28:117-133.

VERCELLINO, I.S. 2001. Sucessão da comunidade de algas perifíticas em dois reservatórios do Parque Estadual das Fontes do Ipiranga, São Paulo: influência do estado trófico e período climatológico. Dissertação de mestrado, Universidade Estadual Paulista, Rio Claro.

VERCELLINO, I.S. 2007. Respostas do perifíton aos pulsos de enriquecimento em níveis crescentes de fósforo e nitrogênio em represa tropical mesotrófica (Lago das Ninféias, São Paulo). Tese de doutorado. UNESP, Rio Claro.

VERCELLINO, I.S. \& BICUDO, D.C. 2006. Sucessão da comunidade de algas perifíticas em reservatório oligotrófico tropical (São Paulo, Brasil): comparação entre período seco e chuvoso. Revista Brasileira de Botânica 29:363-377.

WINTER, J.G. \& DUTHIE, H.C. 2000. Epilithic diatoms as indicators of stream total $\mathrm{N}$ and total $\mathrm{P}$ concentration. Journal of the North American Benthological Society 19:32-49.

ZIMBA, P.V. 1998. The use of nutrient enrichment bioassays to test for limiting factors affecting epiphytic growth in Lake Okeechobee, Florida: confirmation of nitrogen and silica limitation. Archiv für Hydrobiologie 141: 459-468. 